\title{
ANALISIS POTENSI DAN KONTRIBUSI PAJAK BUMI DAN BANGUNAN SEKTOR PERDESAAN DAN PERKOTAAN (PBB P2) DI KABUPATEN GUNUNGKIDUL
}

\author{
Fitriani Hatta \\ Dewi Amalia
}

\begin{abstract}
According to the law number 28 year 2009 on local taxes and levies, building and land tax is 5 types namely $P 2$ and P3. PBB P2 is the rural and urban areas, PBB $P 3$ is the agricultural sector, fisheries, and mining. $P B B P 2$ central tax formerly be transferred to local taxes. The regulation is effective from the beginning of 2014. Several regions had already been made since the transitional PBB P2 2012. One of the regions that conducted the transfer is in Yogyakarta. The purpose of this research was to study, analyze and concluded about potential of tax in Kabupaten Gunungkidul PBB P2 in 2014 and about the contribution of the PBB P2 in Kabupaten Gunungkidul last year until the year 2014. Based on calculations on the results of potential PBB P2 2104 year, the determination of the target and the realization of tax revenue $P B B P 2$ in 2014 is far from the existing potential. A comparison of potential $P B B P 2$ and the target of $P B B P 2$ is $24,49 \%$, it means the determination of the target of $P B B P 2$ is far from the existing potential. A comparison of the potential and the $P B B P 2$ is 21,06 percent, it means the realization of tax revenue $P B B P 2$ is far from the existing potential. In accordance with the results of the calculation of the potential research Abdullah (2012) said that when the budget income, the head of units tend to determine the target under the potential income actually. The calculation on the contribution indicate the percentage of PBB P2 in Kabupaten Gunungkidul from 2011 up to 2013 has been steadily declining. It means the role of $P B B P 2$ or other contributions to the local revenue starting the year 2011 up to 2013 the less. This is because the realization of local revenue in Kabupaten Gunungkidul from 2011 until 2013 also rose, so as to cause the contribution of $P B B P 2$ to local government revenue decline, although the realization of tax revenue PBB P2 increase from year 2011 up to 2013.
\end{abstract}

Keywords: land and building tax sector rural and urban areas (PBB P2), the potential, the contribution of, local revenue.

\section{PENDAHULUAN}

Perpajakan merupakan salah satu bagian terpenting dalam Anggaran Pendapatan dan Belanja Negara (APBN). Hal ini terbukti besarnya kontribusi penerimaan pajak dalam mendanai APBN setiap tahunnya. Tercatat pada tahun 2014 kontribusi pajak dalam mendanai APBN sebesar 43,56\%. Berdasarkan peraturan Undang-Undang Nomor 28 Tahun 2009 tentang Pajak Daerah dan Retribusi daerah, salah satu jenis dari penerimaan pajak adalah Pajak Bumi dan Bangunan (PBB). PBB 
terdapat 5 jenis yaitu P2 dan P3. PBB P2 adalah sektor pedesaan dan perkotaan, dan PBB P3 adalah PBB sektor perkebunan, perhutanan, dan pertambangan.

PBB yang dialihkan menjadi pajak daerah hanya PBB sektor Pedesaan dan Perkotaan (P2), sementara PBB sektor Perkebunan, Perhutanan, dan Pertambangan (P3) masih menjadi pajak pusat. Peralihan PBB P2 dari pajak pusat ke pajak daerah tentunya memberikan peluang dan tantangan tersendiri dalam memaksimalkan penerimaan PBB P2. Peluang yang bisa diperoleh dari peralihan PBB P2 dari pajak pusat ke pajak daerah untuk pemerintahan kabupaten/kota sendiri adalah penerimaan dari PBB sebesar 100\% akan masuk ke pemerintah kabupaten/kota. Peluang tersebut tentunya akan menjadi tantangan tersendiri bagi pemerintah daerah apabila tidak mempersiapkan diri dengan baik.

Pengelolaan potensi PBB P2 yang baik dapat membantu pemerintah daerah untuk menetapkan target PBB P2 sesuai dengan potensi yang ada. Penetapan target tersebut diharapkan dapat meningkatkan realisasi penerimaan PBB P2. Hal ini ditujukan agar penerimaan pajak tersebut dapat memberikan kontribusi yang maksimal terhadap pendapatan daerah di Kabupaten Gunungkidul.

Kabupaten Gunungkidul juga merupakan salah satu daerah yang telah melakukan persiapan peralihan PBB P2 sejak tahun 2012. Oleh karena itu, penulis semakin tertarik untuk mengetahui seberapa besar potensi dan kontribusi dari PBB P2 di Kabupaten Gunungkidul. Hal tersebut diharapkan agar aparat pemerintah yang ada di Kabupaten Gunungkidul dapat mengelola dengan baik potensi PBB P2 yang ada untuk memaksimalkan penerimaan PBB P2 di Kabupaten Gunungkidul. Penerimaan PBB P2 yang maksimal tentunya akan memberikan kontribusi yang maksimal pula terhadap pendapatan daerah di Kabupaten Gunungkidul.

Teknik analisis yang digunakan dalam penelitian ini menggunakan metoda analisis deskriptif dengan pendekatan kuantitatif. Metoda ini dapat membantu pembaca untuk lebih memahami maksud dari data yang ditampilkan mengenai variabel-variabel yang diteliti serta dapat membandingkan target dan realisasi PBB P2. Hal ini dilakukan agar dapat mengetahui potensi dan tingkat kontribusi PBB P2 di Kabupaten Gunungkidul. Berdasarkan latar belakang yang ada penulis tertarik untuk melakukan penelitian tentang analisis potensi dan kontribusi pajak bumi dan bangunan sektor perdesaan dan perkotaan (PBB P2) di Kabupaten Gunungkidul. 


\section{TINJAUAN PUSTAKA DAN HASIL-HASIL PENELITIAN TERDAHULU Pengertian Pajak Bumi dan Bangunan}

Pajak Bumi dan Bangunan (PBB) adalah pajak negara yang dikenakan terhadap bumi dan atau bangunan berdasarkan Undang-Undang Nomor 12 Tahun 1985 tentang Pajak Bumi dan Bangunan sebagaimana telah diubah dengan UndangUndang Nomor 12 Tahun 1994. PBB adalah pajak yang bersifat kebendaan dalam arti besarnya pajak terutang ditentukan oleh keadaan objek yaitu bumi/tanah dan atau bangunan. Keadaan subjek (siapa yang membayar) tidak ikut menentukan besarnya pajak.

Menurut Undang-Undang Nomor 28 Tahun 2009 tentang Pajak Daerah dan Retribusi Daerah, pajak bumi dan bangunan perdesaan dan perkotaan adalah pajak atas bumi dan/atau bangunan yang dimiliki, dikuasai, dan/atau dimanfaatkan oleh orang pribadi atau badan, kecuali kawasan yang digunakan untuk kegiatan usaha perkebunan, perhutanan, dan pertambangan. Bumi adalah permukaan bumi yang meliputi tanah dan perairan pedalaman serta laut wilayah kabupaten/kota. Bangunan adalah konstruksi teknik yang ditanam atau dilekatkan secara tetap pada tanah dan/atau perairan pedalaman dan/atau laut.

Menurut Peraturan Daerah Kabupaten Gunungkidul Nomor 26 Tahun 2012 tentang pajak Bumi dan Bangunan Perdesaan dan Perkotaan, besarnya tarif Pajak ditetapkan sebagai berikut:

a. 0,08\% (nol koma nol delapan per seratus) untuk NJOP sampai dengan Rp1.000.000.000,- (satu milyar rupiah);

b. $0,175 \%$ (nol koma seratus tujuh puluh lima per seratus) untuk NJOP di atas Rp1.000.000.000,- (satu milyar rupiah);

Menurut Peraturan Daerah Kabupaten Gunungkidul Nomor 26 Tahun 2012 tentang pajak Bumi dan Bangunan Perdesaan dan Perkotaan, dasar pengenaan pajak adalah NJOP. Nilai Jual Objek Pajak Tidak Kena Pajak ditetapkan sebesar Rp10.000.000,00 (sepuluh juta rupiah) untuk setiap Wajib Pajak. 


\section{Pendapatan Asli Daerah}

Pengertian pendapatan asli daerah berdasarkan Undang-Undang Nomor 33 Tahun 2004 tentang Perimbangan Keuangan Antara Pusat dan Daerah Pasal 1 angka 18 bahwa pendapatan asli daerah, selanjutnya disebut PAD adalah pendapatan yang diperoleh daerah yang dipungut berdasarkan peraturan daerah sesuai dengan peraturan perundang-undangan. Menurut Undang-Undang Nomor 32 Tahun 2004 tentang Pemerintahan Daerah, pendapatan daerah adalah semua hak daerah yang diakui sebagai penambah nilai kekayaan bersih dalam periode tahun anggaran yang bersangkutan.

Abdullah (2012) menyatakan bahwa ketika menganggarkan pendapatan, kepala SKPD cenderung menentukan target di bawah potensi pendapatan yang sebenarnya. Selisih antara potensi pendapatan yang sesungguhnya dengan target pendapatan yang diusulkan oleh kepala SKPD disebut senjangan atau kesenjagan anggaran (budget slack). Pada konsep penganggaran pendapatan digunakan asas minimal, yakni penetuan target pendapatan sebagai batas terendah yang harus dicapai oleh unit kerja atau pemerintah daerah. Konsep tersebut sering dikenal dengan istilah under estimated untuk pendapatan.

\section{Potensi}

Menurut Kamus Besar Bahasa Indonesia (2011: 1096), potensi adalah kemampuan yang mempunyai kemungkinan untuk dikembangkan, kekuatan, kesanggupan, daya. Perhitungan potensi ditujukan agar pemerintah Kabupaten Gunungkidul dapat menentukan target penerimaan PBB P2 dengan tepat. Hal ini diharapkan dengan pemahaman yang baik mengenai potensi dari PBB P2, Pemerintah Kabupaten Gunungkidul dapat meralisasikan target penerimaan PBB P2 dengan maksimal.

\section{Kontribusi}

Menurut Kamus Besar Bahasa Indonesia (2011: 730), pengertian kontribusi adalah sumbangan. Kontribusi adalah sesuatu yang diberikan bersama-sama dengan pihak lain untuk tujuan biaya, atau kerugian tertentu atau bersama. Kontribusi yang dimaksud dapat diartikan sebagai sumbangan yang diberikan oleh pendapatan PBB 
P2 terhadap besarnya penerimaan pendapatan asli daerah yang diperoleh oleh Kabupaten Gunungkidul.

\section{Hasil-Hasil Penelitian Terdahulu}

Penelitian Sucipto (2013) tentang potensi PBB P2 di Kota Yogyakarta tahun 2012 adalah sebesar Rp45.705.243.283. Jika melihat target penerimaan PBB P2 tahun 2012 yaitu sebesar Rp32.000.000.000 maka dapat diketahui bahwa target penerimaan PBB P2 tahun 2012 adalah sebesar 70,01\% dari potensi PBB P2 Kota Yogyakarta. Selisih potensi dan target yang cukup besar ini menandakan bahwa target PBB P2 yang ditetapkan oleh pemerintah Kota Yogyakarta belumlah optimal dan masih bisa ditingkatkan. Jika membandingkan realisasi penerimaan PBB P2 tahun 2012 yaitu sebesar Rp44.116.129.388 dengan besarnya potensi PBB P2 Kota Yogyakarta tahun 2012 sebesar Rp45.705.243.283 maka dapat diketahui bahwa realisasi penerimaan PBB P2 Kota Yogyakarta tahun 2012 adalah sebesar 96,52\%. Hal ini menunjukkan bahwa realisasi penerimaan PBB P2 tahun 2012 sudah hampir maksimal sesuai dengan besar potensi PBB P2 yang ada di Kota Yogyakarta. Target dan realisasi penerimaan PBB P2 tahun 2012 juga mengalami peningkatan dari tahun sebelumnya.

Kharisma (2013) penerimaan PBB dalam kurun waktu empat tahun dari tahun 2008-2011 terus mengalami peningkatan kecuali pada tahun 2009. Namun, dari target yang diberikan kepada KPP Pratama Manado sudah terealisasikan secara efektif. PBB di KPP Pratama Manado dinilai sudah efektif karena persentasenya di atas 90\%. Hasil penelitian adalah Kontribusi PBB dari data empat tahun terakhir tahun 2008-2011 yaitu persentase rata-rata 5\%, kecuali pada tahun 2010 yaitu $6 \%$. Penelitian ini memiliki metoda yang sama yaitu metoda deskriptif dan memiliki metoda analisis data yaitu analisis kontribusi.

Hasil penelitian Indah (2013) menunjukkan bahwa pelaporan PBB yang dilakukan oleh DPPKAD di Kabupaten Kepulauan Sangihe sudah dilakukan dengan baik. Mekanisme sudah terselesaikan sebelum tanggal jatuh tempo dan dapat dilaporkan ke pusat dengan target pencapaian 100\%. Kontribusi PBB terhadap pendapatan daerah dari tahun 2008-2012 berdasarkan pengukuran kinerja sudah 
memberikan kontribusi positif yang terus meningkat. Penelitian ini memiliki metoda analisis data yaitu analisis kontribusi.

\section{METODA PENELITIAN}

\section{Objek Penelitian}

Penelitian ini dilakukan di Kabupaten Gunungkidul. Objek penelitian dalam penelitian ini adalah Pajak Bumi dan Bangunan sektor Perdesaan dan Perkotaan (PBB P2). Penelitian ini dilakukan untuk mengetahui potensi dan kontribusi dari Pajak Bumi dan Bangunan Perdesaan dan Perkotaan di Kabupaten Gunungkidul.

\section{Sumber Data}

Data sekunder dalam penelitian ini adalah tabel target dan realisasi penerimaan pajak di DPPKAD Kabupaten Gunungkidul selama tahun 2011 sampai tahun 2013. Instansi yang terkait adalah Badan Perencanaan Pembangunan Daerah (BAPPEDA) Kabupaten Gunungkidul, Badan Pusat Statistik (BPS) Kabupaten Gunungkidul, dan Dinas Pendapatan Pengelolaan Keuangan dan Aset Daerah (DPPKAD) Kabupaten Gunungkidul.

\section{Definisi Operasional dan Pengukuran}

Penelitian ini dilakukan untuk mengetahui potensi dan kontribusi PBB P2 terhadap pendapatan daerah di Kabupaten Gunungkidul. Berikut ini penjelasan definisi dan pengukurannya:

1. Potensi PBB P2 adalah besarnya kemampuan suatu wilayah untuk menghasilkan PBB P2 dan memiliki kemungkinan untuk dikembangkan di Kabupaten Gunungkidul. Berikut ini adalah rumus untuk menghitung potensi PBB P2 yaitu dengan cara sebagai berikut (Mardiasmo, 2002: 268):

Potensi PBB P2 = Tarif pajak x [NJOPKP]

Keterangan:

PBB P2 : Pajak Bumi dan Bangunan sektor Perdesaan dan Perkotaan.

Tarif Pajak: Menurut Peraturan Daerah Kabupaten Gunungkidul Nomor 26

Tahun 2012 tentang Pajak Bumi dan Bangunan Perdesaan dan 
Perkotaan, tarif pajak Kabupaten Gunungkidul ditetapkan sebagai berikut:

1) $0,08 \%$ untuk NJOP sampai dengan Rp1.000.000.000,-

2) $0,175 \%$ untuk NJOP di atas Rp1.000.000.000,-

Tarif pajak PBB P2 Kabupaten Gunungkidul akan dikelompokkan sebagai berikut:

1) Kelompok I, tarif 0,08\% untuk NJOP sampai dengan Rp1.000.000.000.

2) Kelompok II, tarif 0,0175\% untuk NJOP di atas Rp1.000.000.000.

Sebelum menghitung besarnya potensi PBB P2 di Kabupaten Gunungkidul, berikut ini adalah tahapan yang dilakukan untuk mengetahui potensi PBB P2 (dalam Adi, 2013):

a. Menghitung total luas Wilayah Potensi Pajak (WPP) di Kabupaten Gunungkidul. Rumus untuk menghitung total luas wilayah potensi pajak sebagai berikut:

Luas WPP= Luas Wilayah - Luas RTHP

b. Melihat data rekap realisasi berdasarkan NJOP dari DPPKAD Kabupaten Gunungkidul untuk mengetahui jumlah wajib pajak dan besar NJOP.

3) Menghitung NJOP rata-rata Kabupaten Gunungkidul dengan menggunakan rumus sebagai berikut:

NJOP rata-rata $=\frac{\sum \text { NJOP rata-rata per Kecamatan }}{\mathrm{N}}$

4) Menghitung NJOP Bumi yaitu dengan rumus:

NJOP Bumi $=$ Luas WPP $\times$ NJOP rata-rata

5) Menghitung NJOP bangunan yaitu dengan rumus:

NJOP Bangunan $=$ Total NJOP Bangunan $\mathrm{x}$ Persentase WP

c. Menghitung besarnya NJOPTKP di Kabupaten Gunungkidul.

d. Menghitung besarnya NJOPKP di Kabupaten Gunungkidul.

e. Menghitung besarnya potensi PBB P2. 
Besarnya Nilai Jual Objek Pajak Tidak Kena Pajak (NJOPTKP) ditetapkan sebesar Rp10.000.000,00 (sepuluh juta rupiah) untuk setiap wajib pajak. NJOPKP adalah nilai jual objek pajak kena pajak, yaitu besaran nilai yang akan dikenai pajak (Peraturan Daerah Kabupaten Gunungkidul Nomor 26 Tahun 2012 tentang Pajak Bumi dan Bangunan Perdesaan dan Perkotaan).

2. Kontribusi

Menurut Mahmudi (2007: 131), rasio ini bermanfaat untuk mengetahui tingkat kontribusi perusahaan daerah dalam mendukung pendapatan daerah. Rasio ini dihitung dengan cara membandingkan penerimaan daerah dari hasil pengelolaan kekayaan daerah yang dipisahkan dengan total penerimaan pendapatan asli daerah. Rasio kontribusi PBB P2 dianggap baik apabila rasio ini minimal 1 atau 100\%. Semakin besar rasio ini maka semakin baik.

Rasio kontribusi ini untuk mengetahui seberapa besar kontribusi PBB P2 terhadap penerimaan pajak di Kabupaten Gunungkidul, maka digunakan rumus sebagai berikut, Mahmudi (2007: 131):

Kontribusi PBB P2 $=\frac{\text { Realisasi Penerimaan PBB P2 }}{\text { Realisasi Pendapatan Asli Daerah }} \quad$ x 100\%

Besarnya persentase hasil perhitungan menunjukkan seberapa besar kontribusi PBB P2 terhadap PAD. Semakin besar persentase kontribusi yang diperoleh menunjukkan semakin besar pula peranan PBB P2 terhadap PAD. Begitu juga sebaliknya, semakin kecil persentase kontribusi yang diperoleh menunjukkan semakin kecil pula peranan PBB P2 terhadap PAD di Kabupaten Gunungkidul.

\section{TEKNIK ANALISIS DATA}

Metoda yang digunakan dalam penelitian ini adalah metoda analisis deskriptif kuantitatif. Penelitian deskriptif menggunakan pendekatan kuantitatif berupa pengumpulan dan pengukuran data yang berbentuk angka. Menurut Cooper (2006: 172) studi deskriptif yang paling sederhana berhubungan dengan pertanyaan atau hipotesis yang bervariasi tunggal. Hal ini membuat peneliti mempertanyakan tentang atau menyatakan suatu tentang, ukuran, bentuk, distribusi, atau eksistensi suatu variabel. Menurut Kuncoro (2009: 12) penelitian deskriptif meliputi pengumpulan 
data untuk diuji hipotesis atau menjawab pertanyaan mengenai status terakhir dari subjek penelitian.

\section{HASIL ANALISIS DAN PEMBAHASAN}

\section{Perhitungan Potensi}

Berdasarkan cara perhitungan yang telah dijabarkan sebelumnya, berikut ini adalah cara perhitungan potensi:

\section{Deskripsi Luas Wilayah Potensi Pajak}

Diketahui bahwa dari $1.485 .360 .000 \mathrm{~m}^{2}$ total luas wilayah Kabupaten Gunungkidul, yang menjadi wilayah potensi pajak di Kabupaten Gunungkidul adalah sebesar $78.650 .000 \mathrm{~m}^{2}$. Berdasarkan perhitungan dapat dilihat bahwa dari 18 Kecamatan yang ada di Kabupaten Gunungkidul, luas wilayah potensi pajak yang paling besar berasal dari Kecamatan Semin yaitu sebesar 19.430.000 $\mathrm{m}^{2}$ dengan luas wilayah 78.920.000 $\mathrm{m}^{2}$. Setelah itu ada Kecamatan Gedangsari dengan luas wilayah potensi pajak sebesar $13.040 .000 \mathrm{~m}^{2}$ dan luas wilayahnya sebesar $68.140 .000 \mathrm{~m}^{2}$. Kemudian setelah itu ada Kecamatan Playen, Ngawen, Ponjong, Karangmojo, Nglipar, Playen, Semanu, Purwosari, Wonosari, Paliyan, Panggang, Tanjungsari, Girisubo, Saptosari, Rongkop, dan terakhir Tepus.

\section{Tabel 1}

Deskripsi Luas Wilayah Potensi Pajak Di Kabupaten Gunungkidul

\begin{tabular}{|l|r|r|r|}
\hline $\begin{array}{c}\text { Tarif } \\
(\%)\end{array}$ & $\begin{array}{c}\text { Wajib Pajak } \\
\text { (Orang) }\end{array}$ & $\begin{array}{r}\text { Persentase WP (\%) } \\
(\mathbf{a})\end{array}$ & $\begin{array}{c}\left.\text { Luas WPP } \mathbf{( m}^{\mathbf{2}}\right) \\
(\mathbf{c})=(\mathbf{a}) *(\mathbf{b})\end{array}$ \\
\hline Kelompok I & 578.711 & 99,96 & 78.618 .540 \\
\hline Kelompok II & 255 & 0,04 & 31.460 \\
\hline Total & 578.966 & 100 & $78.650 .000(\mathrm{~b})$ \\
\hline
\end{tabular}

Sumber: Data sekunder (2015), diolah.

Berdasarkan tabel 1, tarif NJOP sebesar $0,08 \%$ dengan wajib pajak 578.711 orang memiliki luas wilayah potensi pajak sebesar $78.618 .540 \mathrm{~m}^{2}$. Tarif NJOP sebesar 0,175 dengan wajib pajak 255 orang memiliki luas potensi pajak $31.460 \mathrm{~m}^{2}$.

2. Klasifikasi Tarif Pajak dan Jumlah Wajib Pajak

Persentase wajib pajak diperoleh dengan cara mengklasifikasikan tarif pajak dan jumlah wajib pajak berdasarkan nilai jual objek pajak yang telah ditetapkan di 
Kabupaten Gunungkidul. Hasil persentase tersebut diperoleh dengan cara membandingkan wajib pajak berdasarkan klasifikasi nilai jual objek pajak yang telah ditetapkan dengan total seluruh wajib pajak yang terdaftar di DPPKAD Kabupaten Gunungkidul. Setelah itu, hasil perbandingan tersebut kemudian dikalikan $100 \%$. Tarif NJOP Kabupaten Gunungkidul ditentukan berdasarkan Peraturan Daerah Kabupaten Gunungkidul Nomor 26 Tahun 2012 tentang Pajak Bumi dan Bangunan Perdesaan Perkotaan.

Tabel 2

Klasifikasi Tarif Pajak dan Jumlah WP Berdasarkan NJOP

\begin{tabular}{|l|l|r|r|}
\hline \multicolumn{1}{|c|}{$\begin{array}{c}\text { NJOP } \\
(\mathbf{R p})\end{array}$} & \multicolumn{1}{c|}{$\begin{array}{c}\text { Tarif } \\
(\boldsymbol{\%})\end{array}$} & $\begin{array}{c}\text { Wajib Pajak (Orang) } \\
(\mathbf{a})\end{array}$ & $\begin{array}{c}\text { Persentase WP (\%) } \\
(\mathbf{c})=(\mathbf{a}) \mathbf{:}(\mathbf{b}) * \mathbf{1 0 0} \%\end{array}$ \\
\hline $0-1.000 .000 .000$ & Kelompok I & 578.711 & 99,96 \\
\hline$>1.000 .000 .000$ & Kelompok II & 255 & 0,04 \\
\hline Total & & $578.966(\mathrm{~b})$ & 100 \\
\hline
\end{tabular}

Sumber: Data sekunder (2015), diolah.

Berdasarkan tabel 2, tarif pajak dan jumlah wajib pajak diklasifikasikan berdasarkan nilai jual objek pajak yang ada di Kabupaten Gunungkidul. NJOP Rp0 sampai dengan Rp1.0000.000.000 dengan tarif pajak sebesar 0,08\% memiliki jumlah wajib pajak 578.711 orang dengan persentase wajib pajak 99,96\%. NJOP di atas Rp1.000.000.000 dengan tarif pajak sebesar 0,175\% memiliki wajib pajak 255 orang dengan persentase wajib pajak $0,04 \%$.

3. NJOP rata-rata Kabupaten Gunungkidul

Berdasarkan informasi yang diperoleh dari Dinas Pendapatan Pengelolaan Keuangan dan Aset Daerah (DPPKAD) Kabupaten Gunungkidul, Nilai Jual Objek Pajak rata-rata di setiap kecamatan yang ada di Kabupaten Gunungkidul sebesar Rp979.000.

\section{NJOP Bumi}

Nilai jual objek pajak bumi di Kabupaten Gunungkidul diperoleh dengan cara, luas wilayah potensi pajak yang telah diklasifikasikan sesuai dengan tarif pajak kemudian dikalikan dengan nilai jual objek pajak rata-rata di Kabupaten Gunungkidul yaitu sebesar Rp979.000. NJOP Bumi yang dirinci berdasarkan besar tarif yang dikenakan dan jumlah WP: 
Tabel 3

NJOP Bumi Di Kabupaten Gunungkidul

\begin{tabular}{|l|r|r|r|r|}
\hline \multicolumn{1}{|c|}{$\begin{array}{c}\text { Tarif } \\
(\boldsymbol{\%})\end{array}$} & $\begin{array}{c}\text { Wajib } \\
\text { Pajak } \\
(\text { Orang) }\end{array}$ & $\begin{array}{c}\text { Luas WPP }\left(\mathbf{m}^{\mathbf{2}}\right) \\
(\mathbf{a})\end{array}$ & $\begin{array}{c}\text { NJOP rata-rata (Rp) } \\
(\mathbf{b})\end{array}$ & $\begin{array}{c}\text { NJOP Bumi (Rp) } \\
(\mathbf{c})=(\mathbf{a}) *(\mathbf{b})\end{array}$ \\
\hline Kelompok I & 578.711 & 78.618 .540 & 979.000 & 76.967 .550 .660 .000 \\
\hline Kelompok II & 255 & 31.460 & 979.000 & 30.799 .340 .000 \\
\hline Total & 578.966 & 78.650 .000 & & 76.998 .350 .000 .000 \\
\hline
\end{tabular}

Sumber: Data sekunder (2015), diolah.

Berdasarkan hasil perhitungan tabel 3, dapat diketahui bahwa tarif pajak sebesar $0,08 \%$ dengan luas wilayah potensi pajak $78.618 .540 \mathrm{~m}^{2}$ memiliki nilai jual objek pajak bumi sebesar Rp76.967.550.660.000. Tarif pajak sebesar 0,175\% dengan luas wilayah potensi pajak $31.460 \mathrm{~m}^{2}$ memiliki nilai jual objek pajak bumi sebesar Rp30.799.340.000. Total nilai jual objek pajak bumi di Kabupaten Gunungkidul sebesar Rp76.998.350.000.000.

\section{NJOP Bangunan}

Berdasarkan data yang diperoleh dari DPPKAD Kabupaten Gunungkidul, nilai jual objek pajak bangunan Kabupaten Gunungkidul sebesar Rp713.417.262.040.

Tabel 4

NJOP Bangunan

\begin{tabular}{|l|r|r|r|}
\hline $\begin{array}{c}\text { Tarif } \\
(\boldsymbol{\%})\end{array}$ & $\begin{array}{c}\text { Wajib Pajak } \\
\text { (Orang) }\end{array}$ & $\begin{array}{r}\text { Persentase WP (\%) } \\
(\mathbf{a})\end{array}$ & $\begin{array}{r}\text { NJOP Bangunan (Rp) } \\
(\mathbf{c})=(\mathbf{a}) *(\mathbf{b})\end{array}$ \\
\hline Kelompok I & 578.711 & 99,96 & 713.131 .895 .135 \\
\hline Kelompok II & 255 & 0,04 & 285.366 .905 \\
\hline Total & 578.966 & 100 & $713.417 .262 .040(\mathrm{~b})$ \\
\hline
\end{tabular}

Sumber: Data sekunder (2015), diolah.

Berdasarkan hasil perhitungan tabel 4, NJOP bangunan sebesar Rp713.131.895.135 diperoleh dari hasil perkalian persentase wajib pajak 99,96\% dengan NJOP Bangunan Rp713.417.262.040. NJOP bangunan sebesar Rp285.366.905 diperoleh dari hasil perkalian persentase wajib pajak 0,04\% dengan NJOP Bangunan Rp713.417.262.040.

6. Nilai Jual Objek Pajak Tidak Kena Pajak (NJOPTKP)

NJOPTKP adalah besaran nilai yang merupakan batas tertinggi nilai/harga objek pajak yang tidak dikenakan pajak. NJOPTKP yang telah ditetapkan di Kabupaten Gunungkidul sebesar Rp10.000.000 per wajib pajak. Penetapan tersebut 
sesuai dengan Peraturan Daerah Kabupaten Gunungkidul Nomor 26 Tahun 2012 tentang Pajak Bumi dan Bangunan Perdesaan Perkotaan. Nilai jual objek pajak tidak kena pajak diperoleh dengan cara, wajib pajak diklasifikasikan berdasarkan tarif NJOP kemudian dikalikan dengan nilai jual objek pajak tidak kena pajak per wajib pajak.

\section{Tabel 5}

Perhitungan NJOPTKP Dirinci Berdasarkan Besar Tarif

\begin{tabular}{|l|r|r|r|}
\hline $\begin{array}{c}\text { Tarif } \\
(\boldsymbol{\%})\end{array}$ & $\begin{array}{c}\text { Wajib Pajak (Orang) } \\
(\mathbf{a})\end{array}$ & $\begin{array}{c}\text { NJOPTKP per WP (Rp) } \\
(\mathbf{b})\end{array}$ & $\begin{array}{c}\text { NJOPTKP (Rp) } \\
(\mathbf{c})=(\mathbf{a}) *(\mathbf{b})\end{array}$ \\
\hline Kelompok I & 578.711 & 10.000 .000 & 5.787 .110 .000 .000 \\
\hline Kelompok II & 255 & 10.000 .000 & 2.550 .000 .000 \\
\hline Total & 578.966 & & 5.789 .660 .000 .000 \\
\hline
\end{tabular}

Sumber: Data sekunder (2015), diolah.

Berdasarkan perhitungan NJOPTKP dari tabel 5, dapat diketahui bahwa tarif NJOP sebesar $0,08 \%$ dengan wajib pajak 578.711 orang memiliki NJOPTKP Rp5.787.110.000.000. Tarif NJOP sebesar 0,175\% dengan wajib pajak 255 orang memiliki NJOPTKP Rp2.550.000.000.

7. Nilai Jual Objek Pajak Kena Pajak (NJOPKP)

\section{Tabel 6}

\section{Perhitungan NJOPKP Dirinci Berdasarkan Besar Tarif}

\begin{tabular}{|l|r|r|r|r|}
\hline $\begin{array}{c}\text { Tarif } \\
(\%)\end{array}$ & $\begin{array}{c}\text { NJOP Bumi (Rp) } \\
(\mathrm{a})\end{array}$ & $\begin{array}{c}\text { NJOP Bangunan (Rp) } \\
(\mathrm{b})\end{array}$ & $\begin{array}{c}\text { NJOPTKP (Rp) } \\
(\mathrm{c})\end{array}$ & \multicolumn{1}{|c|}{$\begin{array}{c}\text { NJOPKP (Rp) } \\
(\mathrm{d})=(\mathrm{a}+\mathrm{b})-(\mathrm{c})\end{array}$} \\
\hline Kelompok I & 76.967 .550 .660 .000 & 713.131 .895 .135 & 5.787 .110 .000 .000 & 71.893 .572 .555 .135 \\
\hline Kelompok II & 30.799 .340 .000 & 285.366 .905 & 2.550 .000 .000 & 28.534 .706 .905 \\
\hline Total & 76.998 .350 .000 .000 & 713.417 .262 .040 & 5.789 .660 .000 .000 & 71.922 .107 .262 .040 \\
\hline
\end{tabular}

Sumber: Data sekunder (2015), diolah.

Berdasarkan hasil perhitungan NJOPKP pada tabel 6, tarif NJOP sebesar 0,08\% memiliki NJOPKP sebesar Rp71.893.572.555.135. Tarif NJOP sebesar 0,175\% memiliki NJOPKP sebesar Rp28.534.706.905.

8. Potensi PBB P2 Kabupaten Gunungkidul

Perhitungan potensi ditujukan agar pemerintah Kabupaten Gunungkidul dapat menentukan target penerimaan PBB P2 dengan tepat sesuai dengan potensi yang ada. Hal ini diharapkan agar dengan potensi tersebut Pemerintah Kabupaten Gunungkidul dapat meralisasikan target penerimaan PBB P2 dengan maksimal. Menghitung 
besarnya potensi PBB P2 menggunakan rumus sebagai berikut (Mardiasmo, 2001: 240):

Potensi PBB P2 = Tarif pajak x NJOPKP

\section{Tabel 7}

Perhitungan Potensi PBB P2 Di Kabupaten Gunungkidul

\begin{tabular}{|l|r|r|}
\hline \multicolumn{1}{|c|}{$\begin{array}{c}\text { Tarif }(\%) \\
(\mathrm{a})\end{array}$} & $\begin{array}{c}\text { NJOPKP }(\mathrm{Rp}) \\
(\mathrm{b})\end{array}$ & \multicolumn{1}{c|}{$\begin{array}{c}\text { Potensi PBB P2 } \\
(\mathrm{c})=(\mathrm{a}) *(\mathrm{~b})\end{array}$} \\
\hline 0,08 & 71.893 .572 .555 .135 & 57.514 .858 .044 \\
\hline 0,175 & 28.534 .706 .905 & 49.935 .737 \\
\hline Total & 71.922 .107 .262 .040 & 57.564 .793 .781 \\
\hline
\end{tabular}

Sumber: Data sekunder (2015), diolah.

Berdasarkan hasil perhitungan potensi PBB P2 di Kabupaten Gunungkidul pada tabel 7, dapat diketahui bahwa tarif NJOP 0,08\% dengan NJOPKP Rp71.893.572.555.135 memiliki potensi sebesar Rp57.514.858.044. Tarif NJOP 0,175\% dengan NJOPKP Rp28.534.706.905 memiliki potensi sebesar Rp49.935.737. Total potensi PBB P2 Kabupaten Gunungkidul pada tahun 2014 Rp57.564.793.781.

a. Perbandingan potensi dan target penerimaan PBB P2

Berdasarkan tabel 5.10, perhitungan potensi PBB P2 di Kabupaten Gunungkidul sebesar Rp57.564.793.781. Hal ini menunjukkan bahwa jika dibandingkan dengan target penerimaan PBB P2 Kabupaten Gunungkidul pada tahun 2014 yaitu Rp 14.100.000.000, maka persentase potensinya hanya sebesar 24,49\%. Hasil perhitungan menunjukkan target penerimaan PBB P2 Kabupaten Gunungkidul yang ditetapkan tahun 2014 masih jauh dari potensi yang ada.

b. Perbandingan potensi dan realisasi penerimaan PBB P2

Berdasarkan data yang diperoleh dari DPPKAD Kabupaten Gunungkidul realisasi penerimaan PBB P2 Kabupaten Gunungkidul pada tahun 2014 sebesar Rp12.122.565.337. Realisasi tersebut jika dibandingkan dengan hasil perhitungan potensi sebesar Rp57.564.793.781, maka akan menunjukkan persentase potensi sebesar 21,06\%. Hal ini menunjukkan realisasi penerimaan PBB P2 Kabupaten Gunungkidul pada tahun 2014 masih kurang jika dibandingkan dengan potensi yang ada. Oleh karena itu, diharapkan pada tahun selanjutnya para aparat pemda bisa meningkatkan target penerimaan PBB P2 di Kabupaten Gunungkidul sesuai 
dengan potensi yang ada agar realisasi penerimaan PBB P2 bisa lebih maksimal dan sesuai dengan potensi yang ada.

Lebih jelasnya, berikut ini adalah grafik 1 yang menunjukkan perbandingan potensi PBB P2 terhadap target dan realisasi PBB P2 di Kabupaten Gunungkidul pada tahun 2014:

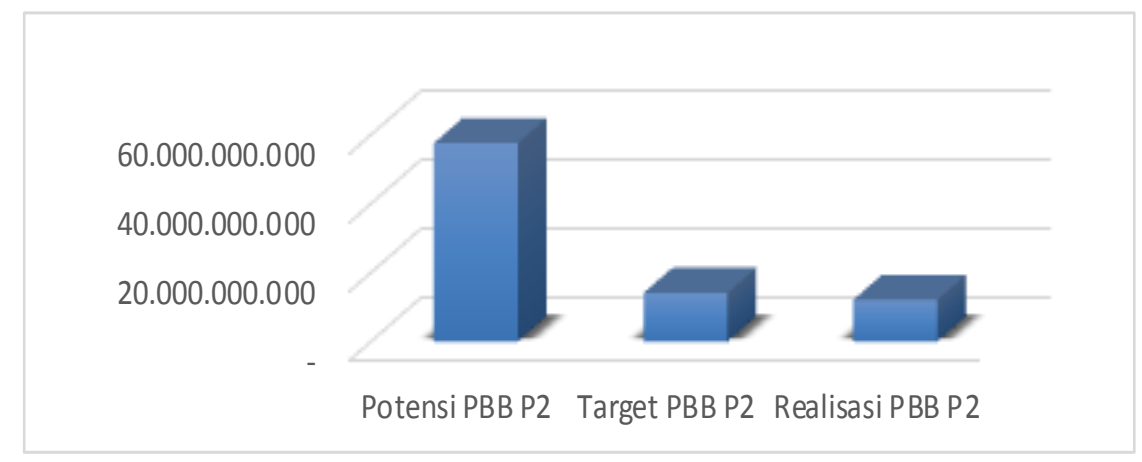

Grafik 1

Perbandingan Potensi dengan Target dan Realisasi PBB P2

Berdasarkan hasil perhitungan dan grafik 1, menunjukkan bahwa penetapan target dan realisasi PBB P2 masih jauh dari potensi PBB P2 yang ada. Penetapan target penerimaan PBB P2 pada tahun 2014 masih belum maksimal, padahal aparat Pemda Kabupaten Gunungkidul bisa lebih meningkatkan lagi target penerimaan PBB P2.

Hasil perhitungan tersebut sesuai dengan penelitian (Abdullah, 2012) yang menyatakan bahwa ketika menganggarkan pendapatan, kepala SKPD cenderung menentukan target di bawah potensi pendapatan yang sebenarnya. Selisih antara potensi pendapatan yang sesungguhnya dengan target pendapatan yang diusulkan oleh kepala SKPD disebut senjangan atau kesenjangan anggaran (budget slack). Diharapkan pada tahun selanjutnya aparat pemda Kabupaten Gunungkidul bisa meningkatkan taget penerimaaan PBB P2 agar realisasi PBB P2 bisa maksimal sesuai dengan potensi yang ada. Peningkatan realisasi PBB P2 juga akan berdampak pada meningkatnya kontribusi PBB P2 terhadap PAD Kabupaten Gunungkidul. 
Perhitungan Kontribusi

\section{Tabel 8}

Perhitungan Kontribusi PBB P2

Di Kabupaten Gunungkidul

\begin{tabular}{|c|c|c|c|}
\hline Tahun & $\begin{array}{c}\text { Realisasi PBB P2 } \\
(\mathrm{Rp})\end{array}$ & $\begin{array}{c}\text { Realisasi PAD } \\
(\mathrm{Rp})\end{array}$ & $\begin{array}{c}\text { Kontribusi } \\
(\%)\end{array}$ \\
\hline 2011 & 8.872 .512 .780 & 54.462 .418 .772 & 16,3 \\
\hline 2012 & 9.253 .321 .043 & 67.050 .781 .893 & 13,8 \\
\hline 2013 & 10.436 .886 .053 & 83.427 .447 .822 & 12,5 \\
\hline
\end{tabular}

Sumber: Data sekunder (2015), diolah.

Berdasarkan perhitungan kontribusi PBB P2 terhadap PAD di Kabupaten Gunungkidul pada tabel 8, dapat diketahui bahwa pada tahun 2011 kontribusi PBB P2 sebesar 16,3\%. Hasil tersebut menunjukkan bahwa kontribusi PBB P2 terhadap PAD Kabupaten Gunungkidul pada tahun 2011 masih kecil, artinya pada tahun tersebut PBB P2 belum maksimal dalam memberikan sumbangan terhadap PAD Kabupaten Gunungkidul. Tahun 2012 kontribusi PBB P2 sebesar 13,8\%, artinya kontribusi PBB P2 terhadap PAD Kabupaten Gunungkidul pada tahun 2012 masih kecil. Angka tersebut jika dibandingkan dengan tahun 2011, persentase kontribusi PBB P2 tahun 2012 menurun sebanyak 2,5\%. Kemudian untuk tahun 2013, kontribusi PBB P2 terhadap PAD Kabupaten Gunungkidul sebesar 12,5\%. Artinya kontribusi PBB P2 masih kecil atau belum maksimal. Dibandingkan dengan tahun 2012, kontribusi PBB P2 pada tahun 2013 menurun sebesar 1,3\%.

Berdasarkan tabel tersebut, tingkat kontribusi PBB P2 mulai tahun 2011 sampai dengan tahun 2013 terus mengalami penurunan. Artinya peranan atau sumbangan PBB P2 terhadap pendapatan asli daerah masih kecil. Hal ini disebabkan karena realisasi pendapatan asli daerah di Kabupaten Gunungkidul dari tahun 2011 sampai dengan tahun 2013 juga meningkat, sehingga menyebabkan kontribusi PBB P2 terhadap PAD menurun, walaupun realisasi penerimaan PBB P2 meningkat dari tahun 2011 sampai dengan 2013.

\section{SIMPULAN, KETERBATASAN, DAN SARAN}

Berdasarkan hasil analisis data dan pembahasan pada bab-bab sebelumnya mengenai analisis potensi dan kontribusi PBB P2 di Kabupaten Gunungkidul, berikut ini adalah simpulan dari peneliti untuk menjawab rumusan masalah yang ada: 
1. Potensi PBB P2 di Kabupaten Gunungkidul pada tahun 2014 sebesar Rp57.564.793.781.

2. Tahun 2011 kontribusi PBB P2 terhadap PAD di Kabupaten Gunungkidul sebesar 16,3\%. Tahun 2012 kontribusi PBB P2 sebesar 13,8\%. Tahun 2013, kontribusi PBB P2 terhadap PAD Kabupaten Gunungkidul sebesar 12,5\%. Hasil perhitungan tingkat kontribusi PBB P2 terhadap pendapatan asli daerah di Kabupaten Gunungkidul dari tahun 2011 sampai dengan tahun 2013 terus mengalami penurunan. Hal ini disebabkan karena realisasi pendapatan asli daerah di Kabupaten Gunungkidul dari tahun 2011 sampai dengan tahun 2013 juga meningkat, sehingga menyebabkan kontribusi PBB P2 terhadap PAD menurun.

Terdapat beberapa hambatan yang ditemui peneliti selama melakukan riset ini yang dapat dijadikan sebagai bahan pertimbangan dalam penelitian berikutnya agar mendapatkan hasil yang lebih baik lagi:

1. Data realisasi penerimaan PBB P2 pada tahun 2014 masih bersifat sementara. Laporan realisasi penerimaan PBB P2 baru selesai diaudit pada bulan Agustus 2015.

2. Data tentang rincian luas wilayah tanah dan/atau bangunan yang dapat dikenakan PBB P2 di Kabupaten Gunungkidul tidak ada, sehingga dalam penelitian ini, besarnya potensi dihitung berdasarkan total luas wilayah Kabupaten Gunungkidul dikurangi dengan luas wilayah untuk RTHP atau bukan merupakan objek pajak bumi dan banguan sektor perdesaan dan perkotaan. Hal ini belum menggambarkan besarnya potensi PBB P2 di Kabupaten Gunungkidul secara akurat.

Berdasarkan simpulan dan keterbatasan yang telah dikemukakan, peneliti menyarankan hal-hal sebagai berikut:

1. Aparat pemerintah daerah sebaiknya menaikkan lagi target penerimaan PBB P2 sesuai dengan potensi yang ada pada tahun selanjutnya. Hal ini bertujuan agar realisasi penerimaan PBB P2 pada tahun selanjutnya lebih maksimal.

2. Pemda Kabupaten Gunungkidul sebaiknya memenuhi kelengkapan pendataan mengenai objek pajak bumi dan bangunan di Kabupaten Gunungkidul untuk meningkatkan target PBB P2 di tahun selanjutnya. 
3. Meningkatkan kegiatan pendataan guna kelengkapan data mengenai Ruang Terbuka Hijau Publik (RTHP). Sebaiknya data mengenai RTHP diperbaharui setiap tahun.

4. Penetapan target penerimaan PBB P2 di Kabupaten Gunungkidul sebaiknya didasarkan pada besarnya potensi luas wilayah tanah dan/atau bangunan yang dapat dikenai pajak sehingga akan lebih memacu untuk menghasilkan PAD yang lebih besar.

\section{DAFTAR PUSTAKA}

Abdullah, Syukry. 2012. Analisis Varian Anggaran Pemerintah Daerah: Penjelasan Empiris dari Perspektif Keagenan. Didapatkan: https://www.academia.edu/9531618/ANALISIS_VARIAN_ANGGARAN_P EMERINTAH_DAERAH_Penjelasan_Empiris_dari_Perspektif_Keagenan [30 Mei 2015].

Sucipto, Adi. 2013. Analisis Potensi PBB P2 di Kota Yogyakarta. Yogyakarta: Universitas Ahmad Dahlan.

Atmasari, Nina. 2014. Harian Jogja [Online]. Didapatkan: file:///D:/kuliah/data\%20skripsi/Harian\%20Jogja\%20\%20\%20Tunggakan\%2 0PBB\%20di\%20Gunungkidul\%20Ada\%20yang\%20Mandeg\%20di\%20Peran gkat $\% 20$ Desa $\% 20$ - 0pajak\% 20bumi\% 20bangunan $\%$ 20gunungkidul $\%$ 20 penyebab $\% \quad 20$ tunggakan $\% \quad 20 \mathrm{pbb} \% \quad 20$ tunggakan $\% \quad 20 \mathrm{PBB} \%$ 20gunungkidul\% 20-Jogjapolitan.htm [14 November 2014].

Cooper dan Wiliam. 1996. Metode Penelitian Bisnis. Edisi 5. Jakarta: Erlangga.

Cooper, Donald. 2006. Metode Riset Bisnis Jilid 1. Jakarta: PT Media Global Edukasi.

Halim, Abdul. 2004. Manajemen Keuangan Daerah. Yogyakarta: AMP YKPN.

Halim, Abdul. 2012. Akuntansi Sektor Publik. Jakarta: Salemba Empat.

http://kamusbahasaindonesia.org/potensi/miripKamusBahasaIndonesia.org[11 Maret 2015].

Indah. 2013. Analisis Pelaporan dan Kontribusi Pajak Bumi dan Bangunan pada Dinas PPKAD Kabupaten Kepulauan Sangihe. Manado: Universitas Sam Ratulangi. Didapatkan: http: //ejournal. unsrat.ac.id/ index.php/ emba/ article/ view/3401 [26 Maret 2015]. 
Departemen Pendidikan Nasional. 2011. Kamus Besar Bahasa Indonesia. Edisi Keempat. 2011. Jakarta: PT Gramedia Pustaka Utama

Kharisma. 2013. Analisis Efektivitas dan Kontribusi PBB terhadap Penerimaan Pajak di KPP Pratama Kota Manado. Manado: Universitas Sam Ratulangi. Didapatkan: http://ejournal.unsrat.ac.id/index.php/emba/article/view/1737 [26 Maret 2015].

Kuncoro, Mudrajad. 2009. Metode Riset untuk Bisnis \& Ekonomi. Jakarta: Erlangga.

Mahmudi. 2007. Analisis Laporan Keuangan Pemerintah Daerah. Yogyakarta: Penerbit dan Percetakan STIM YKPN.

Mardiasmo. 2002. Akuntansi Sektor Publik. Yogyakarta: Andi.

Mardiasmo. 2002. Perpajakan. Yogyakarta: Andi Offset.

Media Keuangan Vol. V No. 40/Desember/2010. Hal. 8. Didapatkan: file:///Page $\% 208 \% 20$ - \% 20mk \%20 desember \% 202010.htm[6 Januari 2015].

Munawir. 1998. Pokok-pokok Perpajakan. Yogyakarta: Liberty.

Pedoman Umum Pengelolaan yang Dikeluarkan oleh Kementerian Keuangan Republik Indonesia Direktorat Jendral Perimbangan Keuangan.

Peraturan Daerah Kabupaten Gunungkidul Nomor 26 Tahun 2012 tentang Pajak Bumi dan Bangunan Perdesaan dan Perkotaan

Resmi, Siti. 2014. Perpajakan. Edisi 8. Jakarta: Salemba Empat.

Situs resmi Bagian Humas dan Protokol Setda Kabupaten Gunungkidul. Didapatkan: http://humasprotokol-gunungkidul.org/halkategori-48-5.html [14>November 2014]

Undang-Undang Nomor 12 Tahun 1994 tentang Pajak Bumi dan Bangunan. Jakarta.

Undang-Undang Nomor 28 Tahun 2009 tentang Pajak Daerah dan Retribusi Daerah. Jakarta.

Undang-Undang Nomor 33 Tahun 2004 tentang Perimbangan Keuangan antara Pemerintah Pusat dan Daerah

Waluyo dan Wirawan. 2000. Perpajakan. Jakarta: Salemba Empat.

Wikipedia. Didapatkan: file://D:/kuliah/data\%20 skripsi/Kabupaten $\% 20$ Gunungkidul\%20-\%20 Wikipedia\%20 bahasa\%20 Indonesia,\%20 ensiklopedia\%20bebas.htm [ 14>November 2014]. 